\title{
The Promise and Perils of CNS Drug Delivery: A Video Debate
}

\author{
Howard E. Gendelman • Alexander Kabanov • James Linder
}

Published online: 6 March 2008

(C) Springer Science + Business Media, LLC 2008

\begin{abstract}
Neurodegenerative and infectious disorders related to host genetics, aging, and environment are rapidly increasing. Drugs, vaccines, or regenerative proteins offer "real" possibilities for positively affecting disease outcomes but are limited by access across the blood-brain barrier. New developments in nanomedicine and cell based drug
\end{abstract}

Electronic supplementary material The online version of this article (doi:10.1007/s11481-008-9103-9) contains supplementary material, which is available to authorized users.

\section{H. E. Gendelman $(\bowtie)$}

Center for Neurovirology and Neurodegenerative Disorders, Departments of Pharmacology and Experimental Neuroscience and Internal Medicine,

University of Nebraska Medical Center, 985880 Nebraska Medical Center, Omaha, NE 68198-5880, USA

e-mail: hegendel@unmc.edu

\section{A. Kabanov}

College of Pharmacy,

Department of Pharmaceutical Sciences, University of Nebraska Medical Center, 986025 Nebraska Medical Center,

Omaha, NE 68198-6025, USA

e-mail: akabanov@unmc.edu

\section{J. Linder}

Department of Pathology and Laboratory Medicine and Eppley Institute for Cancer Research and Allied Diseases, University of Nebraska Medical Center,

Omaha, NE 68105, USA

e-mail: jlinder@unmc.edu delivery are becoming available. These discoveries can lead to improved neurological disease outcomes. Such obstacles include the toxicities inherent in the delivery systems de novo such as immuno- and neurological dysfunctions and perturbations of blood-brain barrier function. This debate by leading experts in the field highlights the promise and perils of CNS drug delivery. Click on Supplemental HTML to watch the streaming video.

\section{Sources}

Batrakova EV, Li S, Reynolds AD, Mosley RL, Bronich TK, Kabanov AV, Gendelman HE (2007) A macrophagenanozyme delivery system for Parkinson's disease. Bioconjug Chem 18:1498-1506

Gilmore JL, Yi X, Quan L, Kabanov AV (2008) Novel Nanomaterials for Clinical Neuroscience. J Neuroimmune Pharmacol. DOI 10.1007/s11481-007-9099-6

Kabanov A, Gendelman H (2007) Nanomedicine in the diagnosis and therapy of neurodegenerative disorders. Progress in Polymer Science 32:1054-1082

Kingsley JD, Dou H, Morehead J, Rabinow B, Gendelman HE, Destache CJ (2006) Nanotechnology: a focus on nanoparticles as a drug delivery system. J Neuroimmune Pharmacol 1:340-350

Maeda H (2001) The enhanced permeability and retention (EPR) effect in tumor vasculature: the key role of tumorselective macromolecular drug targeting. Adv Enzyme Regul 41:189-207 